\title{
DÍVIDA PÚBLICA E CONVERGÊNCIA AOS PADRÕES INTERNACIONAIS DE CONTABILIDADE APLICADOS AO SETOR PÚBLICO (IPSAS)*
}

\begin{abstract}
Diogo Luiz Cordeiro Rodrigues
Doutorando em Direito Econômico e Financeiro pela Faculdade de Direito da USP. Mestre em Direito do Estado pela UFPR, com temporada de pesquisa na Universidade de Toronto, Canadá. Procurador do Estado do Paraná.
\end{abstract}

\begin{abstract}
Introdução - 1. Aspectos teóricos: o processo de convergência aos IPSAS como reflexo da constituição dirigente invertida -2. O processo de convergência aos Padrões Internacionais de Contabilidade Aplicados ao Setor Público (IPSAS): retórica, motivações e reformas mundo afora e no Brasil: 2.1 A retórica oficial dos padrões IPSAS; 2.2 Motivações das reformas: explicações alternativas - 3. A convergência aos IPSAS no Brasil - 4. Dívida pública e convergência aos padrões IPSAS: aportes críticos: 4.1 Literatura estrangeira - 5. Discussão e conclusão: o caso brasileiro - Referências.
\end{abstract}

* N.T.: O presente trabalho, escrito em 2017, contém os frutos iniciais de pesquisa de doutorado realizada pelo autor e permanece válido em seus aspectos gerais, embora não reflita necessariamente os desdobramentos que a pesquisa viria a tomar em etapas posteriores. 


\section{INTRODUÇÃO}

Em 2018, o processo de convergência do Brasil aos Padrões Internacionais de Contabilidade Aplicados ao Setor Público (IPSAS) completou dez anos em meio a muitas incertezas em relação ao impacto dessa importante reforma sobre o sistema de controle das finanças públicas no Brasil, especialmente no que diz respeito à gestão da dívida pública.

O fato é que, apesar de inegáveis avanços, o processo de convergência também suscita uma série de questionamentos, a começar pelo que representa: a introdução de padrões contábeis privatistas, de matriz anglo-americana, que parecem estar voltados preponderantemente à necessidade de atores externos (e não necessariamente, como poderíamos supor, às demandas domésticas por transparência e qualidade dos gastos públicos).

Nesse contexto, meu intuito básico neste artigo é investigar quais são as motivações e os problemas decorrentes do processo de convergência aos padrões IPSAS, tendo em vista a gestão da dívida pública.

O presente trabalho está organizado como segue:

A seção 2 retoma o conceito de Constituição dirigente invertida como ponto de apoio inicial para uma reflexão sobre o telos do processo de convergência aos IPSAS.

A seção 3 é dedicada às motivações básicas para a promoção dos padrões internacionais mundo afora. Nesta parte, inicialmente, são analisados os objetivos dos IPSAS e a retórica usualmente atrelada a sua promoção. Em seguinte, são examinadas as motivações mais comuns por categorias de países.

A seção 4 dedica-se a descrever o processo de convergência aos IPSAS no Brasil.

A seção 5, por seu turno, faz um inventário das críticas mais comuns direcionadas aos padrões internacionais, com ênfase na literatura sobre o caso neozelandês.

A seção 6, por fim, conclui o artigo com uma breve análise sobre os efetivos e eventuais impacto dos IPSAS sobre a gestão da dívida pública brasileira.

\section{ASPECTOS TEÓRICOS: O PROCESSO DE CONVERGÊNCIA AOS IPSAS COMO REFLEXO DA CONSTITUIÇÃO DIRIGENTE INVERTIDA}

A ideia de Constituição dirigente ocupa um espaço central no constitucionalismo brasileiro contemporâneo. Muito além de delinear competências e funções de órgãos públicos e de estabelecer garantias individuais contra eventuais abusos por parte do poder público, a Constituição dirigente é proativa: aponta um estado ideal de coisas a ser atingido pelo Estado, predeterminando em larga medida o 
conteúdo substantivo das leis vindouras, que devem refletir uma concepção ideológica típica do constitucionalismo social, adepto do dirigismo estatal como solução para o combate à desigualdade material e para a promoção do desenvolvimento socioeconômico. A Constituição brasileira de 1988 é rotineiramente apontada como um exemplar de Constituição dirigente, assim como aquela que a teria influenciado de maneira mais direta, qual seja, a Constituição lusitana de $1976^{1}$.

Em 2006, BERCOVICI e MASSONETTO adicionaram um argumento inovador em relação ao caráter dirigente da Constituição de 1988, ao menos em sua vertente financeira. Segundo os juristas, já não teríamos uma Constituição financeira dirigente nos moldes acima indicados, de caráter social, mas sim uma Constituição dirigente invertida, cujo escopo básico seria promover os interesses rentistas do capital financeiro ${ }^{2}$. Explico.

O direito financeiro, de acordo com os autores, teria atravessado três momentos principais em sua história. Inicialmente, durante o liberalismo reinante no século XIX, o direito financeiro seria uma espécie de "subproduto do direito público" tal como então concebido, de modo a "proteger os mercados contra a presença do Estado na economia"3.

Posteriormente, já durante o keynesianismo pós-guerra do Sistema de Bretton Woods, o direito financeiro passaria a formar uma dupla indissociável com o direito econômico. É dizer: as ferramentas do direito financeiro, principalmente o planejamento orçamentário, seriam empregadas, não com o escopo de proteger os mercados, mas sim com a intenção de concretizar o intervencionismo estatal que possibilitaria a promoção do pleno emprego e a redução das desigualdades sociais ${ }^{4}$.

1 Cf. BERCOVICI, Gilberto. A problemática da constituição dirigente: algumas considerações sobre o caso brasileiro. Revista de Informação Legislativa, v. 4, n. 15, 1999. Para um breve resumo do conceito de Constituição dirigente, cf. SARMENTO, Daniel e SOUZA NETO, Cláudio Pereira de. Direito Constitucional - Teoria, História e Métodos de Trabalho. Belo Horizonte: Fórum, 2012, p. $57 / 59$ e 195/198. Quanto à Constituição portuguesa de 1976, vale destacar que Canotilho - difusor do conceito de Constituição dirigente no mundo lusófono - já não a considera dirigista, dadas as transformações recentes pelas quais passa o Estado. Segundo o jurista, a versão atual da Constituição de 1976 seria programática, por definir normas-tarefa e normas-fim, mas sem a pretensão de promover grandes reformas sociais. Nessa linha, além dos autores brasileiros supracitados, cf. CANOTILHO, José Joaquim Gomes. Direito Constitucio-

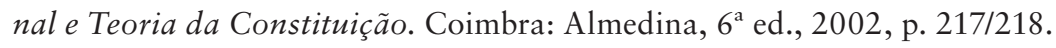

2 Cf. BERCOVICI, Gilberto e MASSONETTO, Luís Fernando. A Constituição Dirigente Invertida: a blindagem da constituição financeira e a agonia da constituição econômica. Boletim de Ciências Económicas, v. XLIX, p. 57-77, 2006.

3 Idem, ibidem, p. 59.

4 Loc. cit. 
Nas últimas décadas do século XX, entretanto, o direto financeiro já não refletiria os anseios do Estado social pós-guerra. Com a financeirização do capitalismo a reboque das crises do petróleo ocorridas nos anos 70, o direito financeiro keynesiano teria sido substituído por uma normatividade hostil ao intervencionismo estatal no domínio econômico ${ }^{5}$. A inovação aportada pelos autores está em chamar atenção para a influência desse processo já na elaboração Constituição financeira de 1988, cujo resultado não seria o de uma Constituição keynesiana no sentido propugnado pela teoria clássica da Constituição dirigente. Em vez disso, a Constituição financeira de 1988 consistiria em um sistema normativo estanque em relação às Constituições social e econômica, ainda progressistas, porém perdidas em uma espécie de limbo normativo. Na verdade, para os autores, a Constituição financeira de 88 refletiria os valores do capitalismo financeirizado da última quadra do século XX, processo iniciado ainda nos anos 70 , com uma tentativa frustrada de insulamento do Banco Central ${ }^{6}$. Nesse contexto, BERCOVICI e MASSONETTO argumentam que a Lei de Responsabilidade Fiscal de 2000 representaria, não o começo, mas o encerramento do processo histórico de reforma do direito financeiro pós-Bretton Woods no Brasil, com enfoque exclusivo no controle de gastos primários em prol da tutela do serviço da dívida, uma suposta garantia da governabilidade do país e de sua credibilidade frente ao mercado internacional. Daí a inversão do nosso dirigismo constitucional, que passa agora a "blindar" a Constituição financeira contra as demandas da política democrática e dos programas ditados pelas Constituições Social e Econômica? .

Mais de dez anos após sua publicação, a importante análise de BERCOVICI e MASSONETTO merece ser revisitada à luz dos eventos em curso no país. Afinal, desde a edição da Lei de Responsabilidade Fiscal, o Brasil tem assistido a inúmeros exemplos de que a Constituição dirigente invertida continua em pleno vigor na seara do direito financeiro, seja por meio da reforma constitucional propriamente dita (caso da Emenda n. 95/2016, a chamada Emenda do Teto de Gastos), seja como força motriz de reformas legais e infralegais de cunho liberalizante, caso do processo de convergência do Brasil aos Padrões Internacionais de Contabilidade Aplicados ao Setor Público (International Public Sector Accounting Standards - IPSAS).

\footnotetext{
Idem, ibidem, p. 60.

6 Idem, ibidem, p. 63.

7 Idem, ibidem, p. 66 e seguintes.
} 


\section{O PROCESSO DE CONVERGÊNCIA AOS PADRÕES INTERNACIONAIS DE CONTABILIDADE APLICADOS AO SETOR PÚBLICO (IPSAS): RETÓRICA, MOTIVAÇÕES E REFORMAS MUNDO AFORA E NO BRASIL}

\subsection{A retórica oficial dos padrões IPSAS}

Os Padrões Internacionais de Contabilidade Aplicados ao Setor Público (IPSAS), como o próprio nome indica, são parâmetros contábeis globais de matriz anglo-americana (ou anglo-saxônica) ${ }^{8}$, com aplicação circunscrita ao setor público em sentido estrito, ou seja, ao que costumamos chamar de órgãos e entidades com personalidade de direito público. Muito embora boa parte dos estudos contábeis brasileiros refira-se aos IPSAS como "normas", prefiro empregar a expressão "padrões", termo que apreende com maior precisão a expressão inglesa original (International Public Sector Accounting Standards). Além disso, vê-se que a escolha do termo "norma" traz embutida uma semântica propositalmente sedutora: quem diz "norma” está a indicar o seu suposto caráter cogente (o que, definitivamente, não é o caso dos IPSAS $)^{10}$. A retórica positiva em torno dos IPSAS, aliás, constitui uma das facetas mais visíveis de sua promoção em escala mundial, como será visto.

Os padrões IPSAS integram um conjunto mais amplo de reformas de tipo liberalizante advogadas pelo movimento conhecido como New Public Management (NPM), vertente teórica que defende a reforma do setor público por meio da implantação de ferramentas empregadas na esfera privada ${ }^{11}$. Tais standards, hoje

8 A origem anglo-saxônica dos padrões IPSAS está bem estabelecida na literatura. Cf., e.g., BRUSCA, Isabel; MONTESINOS, Vicente; CHOW, Danny SL. Legitimating international public sector accounting standards (IPSAS): the case of Spain. Public Money \& Management, v. 33, n. 6, p. 437-444, 2013.

9 Por exemplo, v. MAPURUNGA, Patrícia Vasconcelos Rocha; DE MENESES, Anelise Florencio; PETER, Maria da Glória Arrais. O processo de convergência das normas internacionais de contabilidade: uma realidade nos setores privado e público brasileiros. Revista Controle-doutrinas e artigos, v. 9, n. 1, p. 87-107, 2011.

10 Sobre a carga afetiva da linguagem, cf. NINO, Carlos Santiago. Introdução à Análise do Direito. Trad. Elza Maria Gasparotto. São Paulo: Martins Fontes, 2010, p. 318: “A carga afetiva das expressões linguísticas prejudica seu significado cognitivo, favorecendo sua imprecisão, visto que se uma palavra funciona como uma condecoração ou como um estigma, as pessoas manipulam de maneira arbitrária seu significado para aplicá-lo aos fenômenos que aceitam ou repudiam.”

11 No Brasil, o movimento NPM inspirou a reforma do Estado introduzida em 1995 pelo Plano Diretor da Reforma do Aparelho do Estado e capitaneada em parte, alguns anos mais tarde, pela Emenda Constitucional n. 18/1999, durante o Governo de Fernando Henrique Cardoso. Sobre o processo de reforma do Estado brasileiro à luz da concepção gerencialista, própria do 
em número de 39 padrões válidos, são formulados e revistos pelo Conselho dos Padrões Internacionais de Contabilidade Aplicados ao Setor Público (International Public Sector Accounting Standards Board - IPSASB), colegiado vinculado à Federação Internacional dos Contadores (International Federation of Accountants - IFAC), entidade global de representação contábil, também conhecido por suas normas de auditoria. Tanto o IFAC quanto o IPSASB são entidades de natureza privada e os padrões que editam ou fomentam são largamente inspirados em padrões contábeis aplicados às companhias privadas de capital aberto: dos parâmetros vigentes, apenas 5 não correspondem aos - tampouco foram inspirados pelos - chamados Padrões Internacionais de Contabilidade (International Financial Reporting Standards - IFRS) editados para o setor privado pelo Conselho dos Padrões Internacionais de Contabilidade (International Accounting Standards Board - IASB) ${ }^{12}$.

NPM, cf. BRESSER-PEREIRA, Luiz Carlos. A reforma gerencial do Estado de 1995. Revista de administração pública, v. 34, n. 4, p. 7-26, 2000. Para uma visão crítica, cf. MATIASPEREIRA, José. Administração pública comparada: uma avaliação das reformas administrativas do Brasil, EUA e União Européia. Revista de Administração Pública, v. 42, n. 01, p. 61/82, 2008. Sobre a relação entre os padrões IPSAS e o movimento NPM, cf. BRUSCA, Isabel; GÓMEZ-VILleGAS, Mauricio; MONTESINOS, Vicente. Public Financial Management Reforms: The Role of Ipsas in Latin-America. Public Administration and Development, v. 36, n. 1, p. 51-64, 2016.

12 Segundo BRUSCA, Isabel; GÓMEZ-VILLEGAS, Mauricio; MONTESINOS, Vicente. Public Financial Management Reforms: The Role of Ipsas in Latin-America. Op. cit., p. 52/53, os padrões IPSAS seriam 38 (trinta e oito) ao todo à época da publicação do trabalho. Desses padrões, apenas 6 (seis) deles não corresponderiam a padrões aplicáveis ao setor privado. Sua contagem de padrões puramente públicos, todavia, inclui o padrão IPSAS 32, destinado às concessões de serviços públicos, que se baseia em uma interpretação fornecida pelos pronunciamentos IFRIC 12 e SIC-29, ambos editados pelo IASB, órgão emissor dos padrões IFRS. Segundo pude apurar em consulta ao website do IFAC, outros 2 padrões IPSAS foram publicados após o trabalho de BRUSCA e outros, quais sejam: o IPSAS 39, editado em substituição ao IPSAS 25 para dar novo tratamento aos benefícios de empregados, e o IPSAS 40, dedicado às combinações (rectius: reestruturações) do setor público, nomeadamente o amalgamento de entidades ou a aquisição de uma entidade pública por outra. Tanto o IPSAS 39 quanto o IPSAS 40 derivam ou se inspiram em padrões IFRS. Considerando que o IPSAS 39 substitui um padrão preexistente (o de n. 25), chega-se ao número total de 39 IPSAS válidos, sendo 5 deles sem correspondência em qualquer padrão IFRS ou interpretação fornecida pelo IASB. Os IPSASs 39 e 40 entrarão em vigor nos dias 1\%1/18 e 1\%1/19, respectivamente. Os IPSASs 32, 39 e 40 podem ser consultados por meio dos seguintes endereços: <http://www.ifac.org/system/files/ publications/files/B8\%20IPSAS_32.pdf >; <https://www.ifac.org/system/files/publications/files/IPSASB-At-a-Glance-IPSAS-39.pdf>; <https://www.ifac.org/system/files/publications/files/ IPSASB-IPSAS-40-Public-Sector-Combinations-At-a-Glance.pdf> (acesso em 07/12/17). 
Convém destacar que os IPSAS constituem padrões de contabilidade geral (ou patrimonial), cuja finalidade principal, portanto, é retratar, com base no regime de competência, o conjunto de operações que afetem o patrimônio, a situação financeira e o resultado da entidade ${ }^{13}$. Assim, o âmbito de aplicação dos IPSAS não se confunde com o da contabilidade orçamentária ${ }^{14}$ ou com o da contabilidade fiscal (ou estatísticas fiscais) ${ }^{15}$, muito embora a denominada Estrutura Conceitual (Conceptual Framework) editada pelo IPSASB aluda ao orçamento público ${ }^{16}$ e enfatize a necessidade de que a contabilidade patrimonial de caráter microeconômico seja integrada às estatísticas fiscais macroeconômicas, o que de certo modo é compreensível, dadas as inevitáveis sobreposições entre os subsistemas contábeis $^{17}$. A bem da verdade, de acordo com BRUSCA, MONTESINOS e CHOW, a agenda do IFAC caminha no sentido de que os padrões IPSAS constituam o núcleo central de um sistema global contábil multifacetado, que seria graficamente representável da seguinte maneira ${ }^{18}$ :

13 Nessa linha, cf. FEIJÓ, Paulo Henrique; CARVALHO JÚNIOR, Jorge Pinto de; RIBEIRO, Carlos Eduardo. Entendendo a Contabilidade Orçamentária Aplicada ao Setor Público. Brasília: Editora Gestão Pública, 2015, p. 73.

14 Segundo Feijó, Carvalho Junior e Ribeiro, "interessa à contabilidade orçamentária o controle de disponibilidades e obrigações orçamentárias, isto é, o total de recursos financeiros que podem ser aplicados em políticas públicas e obrigações do governo”. Ainda segundo os estudiosos, "utilizando a teoria dos fluxos e estoques da contabilidade, pode-se associar que a contabilidade orçamentária tem como objeto o orçamento público" (Idem, ibidem, p. 67/68)

15 De acordo com a Estrutura Conceitual IPSAS convergida pelo Conselho Federal de Contabilidade, "os relatórios de EFP [Estatísticas de Finanças Públicas] são utilizados, principalmente, para: (a) analisar opções de política fiscal, definir essas políticas e avaliar os seus impactos; (b) determinar o impacto sobre a economia; e (c) comparar os resultados fiscais nacional e internacionalmente. O foco é sobre a avaliação do impacto do SGG e do setor público em geral sobre a economia, no âmbito da estrutura conceitual das estatísticas macroeconômicas”. Cf. CONSELHO FEDERAL DE CONTABILIDADE. NBC TSP - Estrutura Conceitual. Prefácio. Brasília, 2016. O documento encontra-se disponível em <http://www2.cfc.org.br/sisweb/sre/detalhes_sre.aspx?COdigo=2016/NBCTSPEC\&arquivo=NBCTSPEC.doc $>$ (acesso em 07/12/17).

16 Idem, ibidem, itens 8 e 9, entre outros. Vale ressaltar que o padrão IPSAS 24 trata exclusivamente da relação entre contabilidade e orçamento público. Cf. INTERNATIONAL FEDERATION OF ACCOUNTANTS. Handbook of International Public Sector Accounting Pronouncements, v. 1, jan., 2016, p. 828-853. Disponível em <http://www.ifac.org/publications-resources/2016-handbook-international-public-sector-accounting-pronouncements $>$ (acesso em 07/12/2017).

17 Idem, ibidem, item 22.

18 Cf. BRUSCA, Isabel; MONTESINOS, Vicente; CHOW, Danny SL. Legitimating international public sector accounting standards (IPSAS): the case of Spain. Public Money \& Management, v. 33, n. 6, p. 437-444, 2013. 


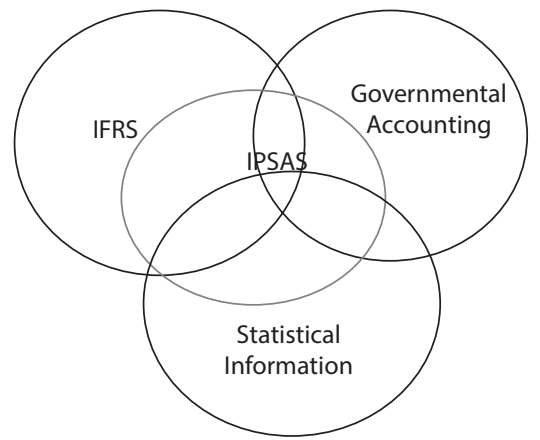

\section{Figura 1}

Oficialmente, a missão do IFAC é promover padrões globais de alta qualidade, baseados no regime de competência, para a confecção dos demonstrativos contábeis ou "relatórios financeiros de propósito geral", como são denominados na linguagem das IPSAS. Ao fazê-lo, o IFAC acredita fomentar transparência e accountability nos sistemas públicos de informação financeira ao redor do mundo, uma vez que os IPSAS conteriam critérios para a geração de dados fiéis, compreensíveis e comparáveis a uma série de usuários nacionais e internacionais. Com isso, além de prevenirem a ocorrência de fraudes, os padrões IPSAS contribuiriam também para a solução da crise das dívidas soberanas, uma vez que o regime de competência seria fundamental para prover um cenário mais completo da posição financeira das entidades públicas, bem como de seu desempenho periódico ${ }^{19}$. A pretensão de influir na estabilidade financeira global e na gestão da dívida pública soberana justificariam o já mencionado entrelaçamento com os padrões contábeis privados e com as estatísticas fiscais macroeconômicas ${ }^{20}$

19 Cf. INTERNATIONAL FEDERATION OF ACCOUNTANTS - IFAC. IPSASB Strategy Consultation, 2014, p. 10/11. Disponível em < http://www.ifac.org/system/files/publications/ files/IPSASB-Strategy-Consultation-2015-2019_0.pdf> (acesso em 08/12/2017). Quanto à literatura contábil, em sentido semelhante, cf. e.g. MAPURUNGA, Patrícia Vasconcelos Rocha; DE MENESES, Anelise Florencio; PETER, Maria da Glória Arrais. O processo de convergência das normas internacionais de contabilidade: uma realidade nos setores privado e público brasileiros. Op. cit., passim.

20 Tal entrelaçamento, aliás, foi expressamente mencionado pela Comissão Europeia em relatório de 2013, destinado a reportar e avaliar em que medida a introdução dos IPSAS como regime contábil comum na União Europeia poderia conferir consistência aos dados microeconômicos dos quais seriam geradas as estatísticas fiscais macroeconômicas relacionadas ao controle da dívida. Cf. COMISSÃO EUROPEIA. Relatório da Comissão ao Conselho e ao Parlamento relativo à aplicação de normas de contabilidade harmonizadas do setor público nos Estados- 
Como se pode perceber, o pilar central dos padrões IPSAS é o dito princípio da competência, inspirador do regime (ou base) de competência contábil, um dos critérios existentes na ciência contábil para a determinação do momento em que devem ser registrados os fatos contábeis.

O regime de competência, conhecido em língua inglesa como accrual accounting, estabelece que "os efeitos das transações e outros eventos sejam reconhecidos nos períodos a que se referem, independentemente do recebimento ou pagamento", pressupondo "a simultaneidade da confrontação de receitas e de despesas correlatas" 21 . Dessa maneira, distingue-se do regime de caixa, que somente considera as receitas e despesas no momento de seu efetivo ingresso ou saída, a depender do caso ${ }^{22}$.

O termo empregado em língua inglesa para o regime de competência (accrual accounting) favorece a compreensão do conceito. O verbo to accrue, em inglês, deriva do francês arcaico acrue e do latim accrescere, significando crescer, incrementar ou aumentar periodicamente, em decorrência de processo natural ou recebimento de juros. Remonta à Alta Idade Média, quando o agricultor percebia o enriquecimento de seu patrimônio à medida que sua cultura crescia. Eis, assim, o espírito básico do regime de competência: capturar o desempenho do patrimônio a partir de suas variações periódicas, independentemente das transações financeiras a que podem dar origem no futuro ${ }^{23}$.

Especificamente, defende-se que o regime contábil de competência ofereceria benefícios como a apreensão de ativos e passivos não financeiros (e.g. bens imóveis recebidos ou entregues em doação) ${ }^{24}$, além do fornecimento de dados sobre desempenho e custos dos serviços públicos ${ }^{25}$. ANESSI-PESSINA e STECCOLINI

-Membros. COM (2013) 114, 2013. Disponível em: <http://eur-lex.europa.eu/legal-content/ EN/TXT/?qid=1410447825715\&uri=CELEX:52013DC0114> (acesso em 07/12/17).

21 FEIJÓ, Paulo Henrique. Entendendo as Mudanças na Contabilidade Aplicada ao Setor Público. Brasília: Editora Gestão Pública, 2013, p. 125.

22 Cf. CARVAlHO, José Augusto Moreira de. Arts. 34 a 39. In: CONTI, José Mauricio (coord.). Orçamentos Públicos: a Lei 4.320/1964 Comentada. São Paulo: Ed. Revista dos Tribunais, 2014, p. 135.

${ }^{23}$ Cf. BORGES, Thiago Bernardo et al. Desmistificação do regime contábil de competência. Revista de Administração Pública-RAP, v. 44, n. 4, 2010.

${ }^{24}$ FEIJÓ, Paulo Henrique; CARVALHO JÚNIOR, Jorge Pinto; RIBEIRO, Carlos Eduardo. Entendendo a Contabilidade Orçamentária Aplicada ao Setor Público. Brasília: Gestão Pública, 2015, p. 63.

${ }_{25}$ MAGALHÃES, Fábio Rodrigues et al. NBCASP e IPSAS: uma análise do processo de convergência brasileira sob a ótica do accrual basis accounting. Revista Brasileira de Contabilidade, n. 201, p. 56-67, 2013. 
apresentam uma ampla lista sobre as vantagens do regime de competência frente ao regime de caixa ${ }^{26}$ :

i) ênfase no controle de custos, mensuração, eficiência e produtividade;

ii) definição das tarifas dos serviços públicos com maior facilidade;

iii) maior atenção na gestão dos ativos;

iv) informações mais completas do passivo das organizações públicas;

v) possibilidade de medir o impacto das políticas públicas com foco no longo prazo;

vi) ênfase na mensuração da equidade intergeracional;

vii) melhor avaliação das escolhas como privatização e empréstimos;

viii) possibilidade de os gestores melhorarem a avaliação de desempenho no serviço público.

Dadas as vantagens apontadas, muitos estudos assumem que a adesão aos padrões IPSAS representaria uma evolução natural para o setor público, motivo suficiente para a implementação de reformas ${ }^{27}$. Mas, afinal, o que motivaria Estados soberanos a aderir voluntariamente aos padrões IPSAS? Seria apenas o apelo da retórica oficial do IFAC em prol de transparência e accountability, como advogam os partidários da New Public Management? A adesão aos IPSAS seria motivada somente pela suposta qualidade técnica de seus padrões? Quão verdadeiro é tal discurso? É o que passo a responder na sequência.

\subsection{Motivações das reformas: explicações alternativas}

Os padrões IPSAS, como já adiantado, não possuem natureza de direito formal válido (hard law). Na verdade, constituem parâmetros técnicos cuja efetividade depende de adesão expressa, em maior ou menor grau, por parte das próprias entidades de direito público nacional ou internacional. Nesse contexto, diferentes estudos têm sido conduzidos com o escopo de determinar quais motivos levariam Estados soberanos a reformar seus sistemas contábeis conforme o modelo IPSAS.

${ }^{26}$ ANESSI-PESSINA, E. and STECCOLINI, I. Effects of Budgetary and Accruals Accounting Coexistence: Evidence from Italian Local Governments. Financial Accountability \& Management, Vol. 23, No. 2, 2007, p. 114 apud ANDRADE, Maria Elisabeth Moreira Carvalho; CARVALHO, Luiz Nelson Guedes de. Análise da adoção do regime de competência no setor público internacional. Revista FSA (Faculdade Santo Agostinho), v. 10, n. 1, 2013, p. 42.

27 FEIJÓ, Paulo Henrique. Entendendo as Mudanças na Contabilidade Aplicada ao Setor Público. Op. cit., passim. 
A partir da análise da literatura comparada em matéria de contabilidade governamental, parece razoável supor um cenário em que a promoção dos padrões IPSAS integre um processo regulatório global mais amplo movido pela ideologia anglo-americana, a envolver diferentes atores do capitalismo global em prol da redução dos custos de transação que as fronteiras nacionais impõem à movimentação dos fluxos financeiros. Nesse contexto, o grau de adesão aos padrões internacionais de contabilidade varia conforme a posição do país no cenário global.

Em síntese, é possível distribuir os países em quatro grupos diversos: (i) o grupo anglófono, composto por países desenvolvidos capitaneados pelo Reino Unido; (ii) o grupo dos países em desenvolvimento; (iii) o grupo europeu continental e, por fim, (iv) os Estados Unidos da América como uma categoria à parte.

O primeiro grupo, integrado por Reino Unido, Nova Zelândia e Austrália, é um aliado de primeira hora das reformas do New Public Management e sua motivação principal, aparentemente, é de ordem cultural-ideológica. Não é de se estranhar, portanto, que constitua o grupo mais simpático à adoção voluntária dos padrões internacionais contábeis em seus respectivos sistemas domésticos. Curiosamente, até pouco tempo atrás, nenhum deles adotava os padrões IPSAS especificamente, ou seja, todos aderiam aos padrões privados IFRS com adaptações específicas para o setor público, o que, na prática, faziam com que seus sistemas contábeis fossem bastante semelhantes ao modelo IPSAS ${ }^{28}$.

O cenário muda drasticamente quando se trata dos países em desenvolvimento. Aqui, percebe-se claramente que as reformas ocorrem a reboque de pressões oriundas de agentes externos, geralmente em conjunto com o anseio dos países de demonstrar credibilidade aos mercados internacionais credores, pelo menos formalmente.

Emblemático, nesse aspecto, é o trabalho de BRUSCA, GÓMEZ-VILLEGAS e MONTESINOS ${ }^{29}$. Embora a atuação da profissão contábil e das grandes firmas de auditoria tenham sido determinantes para a difusão dos padrões IFRS

28 A não adoção inicial dos padrões IPSAS deve-se muito provavelmente ao pioneirismo desses países na adoção de critérios contábeis globais. Hoje, todavia, a Nova Zelândia é adepta dos IPSAS. Nesse sentido, cf. NEWBERRY, Susan. The use of accrual accounting in New Zealand's central government: Second thoughts. Accounting, Economics and Law, v. 4, n. 3, p. 283-297, 2014. Em contraste, Reino Unido e Austrália continuam a adotar os padrões IFRS com adaptações. Sobre o caso britânico, v. JONES, Rowan; CARUANA, Josette. A perspective on the proposal for European public sector accounting standards, in the context of accruals in UK government accounting. Accounting, Economics and Law, v. 4, n. 3, p. 265-282, 2014.

29 BRUSCA, Isabel; GÓMEZ-VILLEGAS, Mauricio; MONTESINOS, Vicente. Public Financial Management Reforms: The Role of Ipsas in Latin-America. Public Administration and Development, v. 36, n. 1, p. 51-64, 2016. 
no setor privado ${ }^{30}$, BRUSCA, GÓMEZ-VILLEGAS e MONTESINOS minimizam a influência desses atores quanto à propagação dos IPSAS. Segundo os autores, organizações internacionais como o FMI e o Banco Mundial é que exerceriam influência determinante para reformas no âmbito doméstico, seja por meio da promoção em si dos padrões IPSAS, seja por meio da adoção dos standards em suas próprias estruturas de governança ${ }^{31}$. A partir de pesquisa bibliográfica e de entrevistas conduzidas com agentes-chave dos governos peruano e colombiano, os autores verificaram que o interesse principal dessas agências multilaterais seria monitorar de maneira mais efetiva a condução da política econômica dos países, de modo a assegurar o êxito de reformas estruturais, programas de estabilização macroeconômica e projetos de fomento financiados com recursos externos ${ }^{32}$. Por outro lado, dentre os agentes entrevistados, um deles mencionou a importância da incorporação dos padrões IPSAS para efeito de melhoria dos ratings indicados pelas agências de classificação de risco, diminuindo-se, assim, os custos das operações de crédito realizadas por seu país. No entanto, aponta-se também que a adoção dos padrões IPSAS na Colômbia e no Peru tem sido preponderantemente formal e retórica, não havendo evidências de que efetivamente contribuam para o aumento da transparência e do processo de accountability naqueles países ${ }^{33}$.

O Brasil, por natural, reproduz o padrão de assimilação encontrado nos demais países em desenvolvimento. Por um lado, nota-se que a retórica de modernização das contas públicas ecoa nas publicações oficiais e em boa parte da litera-

${ }^{30}$ Nessa linha, cf. BOTZEM, Sebastian. The Politics of Accounting Regulation: Organizing Transnational Standard-Setting in Financial Reporting. Cheltenham: Edward Elgar, 2014, passim.

31 No mesmo sentido, BRUSCA, Isabel; MONTESINOS, Vicente; CHOW, Danny SL. Legitimating international public sector accounting standards (IPSAS): the case of Spain. Op. cit., itens 2.2 e 2.3 .

32 Vale destacar que ainda nos anos 90, antes da consolidação dos padrões IPSAS, o FMI e o Banco Mundial já recomendavam ativamente a incorporação dos padrões privados IAS/IFRS por parte dos Estados nacionais. Nessa linha, cf. BOTZEM, Sebastian. The Politics of Accounting Regulation: Organizing Transnational Standard-Setting in Financial Reporting. Op cit., p. 12/13; NEU, Dean; OCAMPO, Elizabeth. Doing missionary work: The World Bank and the diffusion of financial practices. Critical Perspectives on Accounting, v. 18, n. 3, p. 363-389, 2007.

33 O estudo corrobora os achados de ADHIKARI, Pawan; KURUPPU, Chamara; MATILAL, Sumohon. Dissemination and institutionalization of public sector accounting reforms in less developed countries: A comparative study of the Nepalese and Sri Lankan central governments. In: Accounting Forum. Elsevier, 2013. p. 213-230. Para uma análise mais ampla sobre a reforma contábil nos países em desenvolvimento, v. HOPPER, Trevor; LASSOU, Philippe; SOOBAROYEN, Teerooven. Globalisation, accounting and developing countries. Critical Perspectives on Accounting, v. 43, p. 125-148, 2017. 
tura contábil ${ }^{34}$. Por outro lado, também parece razoável supor que as pressões externas e o anseio de alinhamento com os mercados exerçam um papel importante no processo de convergência do país aos IPSAS.

O terceiro grupo, composto pelos países da Europa continental, é marcado pela conhecida tensão entre a preservação da soberania nacional com as necessidades da integração regional estipuladas pela União Europeia. Do ponto de vista da União, a motivação básica para a reforma do sistema contábil parece estar associada à necessidade de que as estatísticas fiscais adotadas para o controle do déficit e da dívida pública sejam amparadas por informações contábeis mais confiáveis e uniformes, com base no regime de competência.

Em 2011, o Conselho Europeu (European Council) emitiu a Diretiva 2011/85/EU, a fim de estipular regras específicas relativas às características dos quadros orçamentários dos Estados-Membros. Em seus consideranda, o Conselho afirmou que "A existência de práticas de contabilidade pública exaustivas e fiáveis em todos os subsectores da administração pública constitui um pré-requisito para a elaboração de estatísticas [fiscais] de elevada qualidade que sejam comparáveis entre os Estados-Membros”. Nesse contexto, o art. $3^{\circ}$ da Diretiva estabeleceu que "os Estados-Membros devem criar sistemas contabilísticos que abranjam, de forma integral e coerente, todos os subsectores da administração pública e contenham as informações necessárias para gerar dados de exercício [accrual data], com vista à elaboração dos dados baseados no SEC 95”, ou seja, o sistema de estatísticas fiscais da Europa. Ainda, o art. 16, item 3, da Diretiva determinou à Comissão Europeia que avaliasse a pertinência dos padrões IPSAS para os membros da União Europeia ${ }^{35}$.

Em resposta, a Comissão Europeia publicou o relatório COM/2013/0114, no qual reconheceu que os IPSAS “constituem uma referência incontornável para o estabelecimento de contas harmonizadas do setor público na UE”, não obstante alguns problemas detectados, como imprecisão e instabilidade dos padrões, além da participação insuficiente das autoridades contabilísticas do setor público da UE na governança dos IPSAS. Desse modo, a Comissão Europeia sugeriu a criação de padrões contábeis europeus confeccionados com base no modelo IPSAS, os European Public Sector Accounting Standards (EPSAS) ${ }^{36}$.

\footnotetext{
${ }^{34}$ E.g. FEIJÓ, Paulo Henrique. Entendendo as Mudanças na Contabilidade Aplicada ao Setor Público. Brasília: Editora Gestão Pública, 2013.

35 CONSELHO EUROPEU. Diretiva 2011/85/EU do Conselho. Disponível em: <http:/leur-lex.europa.eu/legal-content/EN/TXT/?uri=uriserv:OJ.L_.2011.306.01.0041.01.ENG> (acesso em 07/12/17).

36 COMISSÃO EUROPEIA. Relatório da Comissão ao Conselho e ao Parlamento relativo à aplicação de normas de contabilidade harmonizadas do setor público nos Estados-Membros. Op. cit., passim.
} 
A reforma, no entanto, é vista com desconfiança por autoridades e acadêmicos europeus ciosos das particularidades próprias de seus países, a exemplo da primazia do orçamento público e da importância do regime contábil de caixa para o controle doméstico das finanças pela via parlamentar ${ }^{37}$.

Por fim, como sói acontecer, os Estados Unidos encontram-se em situação singular. Aqui, trata-se de questionar o motivo para a não adoção dos IPSAS ou equivalentes, já que o país segue critérios próprios, sem qualquer relação com aqueles adotados pela iniciativa privada ${ }^{38}$. Ao que parece, o órgão regulador federal para a área contábil considera que os standards privados são inadequados para o setor público federal, uma vez que enfatizam os usuários externos à entidade (e.g. investidores). Por outro lado, na visão do órgão, a contabilidade pública federal deve enfatizar o usuário interno, tendo em vista a necessidade de preservação da integridade orçamentária do Estado ${ }^{39}$.

\section{A CONVERGÊNCIA AOS IPSAS NO BRASIL}

No Brasil, o processo de convergência aos padrões internacionais de contabilidade teve início em 2004, quando o Conselho Federal de Contabilidade (CFC) instituiu um grupo de estudos com a finalidade de analisar, elaborar e propor normas técnicas de contabilidade aplicadas ao setor público que fossem alinhadas com os padrões IPSAS ${ }^{40}$. Segundo FEIJÓ, esse grupo contemplava representantes da academia e da burocracia, como participantes da Secretaria do Tesouro Nacional, Secretaria-Executiva do Ministério da Fazenda e Tribunais de Contas ${ }^{41}$.

É importante consignar que o processo de aproximação da contabilidade brasileira com os padrões internacionais foi desmembrado em duas frentes. Em uma primeira frente, decidiu-se promover o que foi batizado como alinhamento aos

37 As principais críticas serão detalhadas na seção 5 deste artigo. Por todos, cf. BIONDI, Yuri. Harmonising European public sector accounting standards (EPSAS): issues and perspectives for Europe's economy and society. Accounting, Economics and Law, v. 4, n. 3, p. 165-178, 2014.

38 Nesse sentido, Jones e outros afirmam que "the US policies are not explicitly based on business accounting policies (or on those for US state and local government)". Vale pontuar, contudo, que o sistema contábil americano é baseado no regime de competência, à exceção do sistema orçamentário. Cf. JONES, Rowan et al. A comparison of budgeting and accounting reforms in the national governments of France, Germany, the UK and the US. Financial Accountability o Management, v. 29, n. 4, p. 419-441, 2013.

39 Idem, ibidem, p. 432/433.

40 Cf. FEIJÓ, Paulo Henrique. Entendendo as Mudanças na Contabilidade Aplicada ao Setor Público. Brasília: Editora Gestão Pública, 2013, p. 53.

${ }^{41}$ Idem, ibidem, p. 54. 
padrões internacionais. O propósito básico, aqui, seria editar normas técnicas brasileiras que refletissem o espírito do modelo IPSAS. Paralelamente, seria buscada a convergência aos padrões IPSAS. Nessa etapa, as normas alinhadas seriam paulatinamente substituídas por normas individualmente convergidas a um correspondente padrão IPSAS, preservadas as particularidades do contexto brasileiro ${ }^{42}$.

De 2007 a 2014, o CFC editou 11 normas no bojo do processo de alinhamento. Atualmente, há 24 normas contábeis técnicas aplicáveis ao setor público, das quais 22 já constituem normas convergidas aos padrões IPSAS. As demais normas são remanescentes do processo de alinhamento. Vejamos:

\section{Quadro 1}

\begin{tabular}{|c|c|c|c|}
\hline & & & CORRELAÇÃO \\
\hline NBC & RESOLUÇÃO CFC & NOME DA NORMA & IFAC \\
\hline $\begin{array}{l}\text { NBC TSP ESTRUTURA } \\
\text { CONCEITUAL }\end{array}$ & DOU 04/10/16 & $\begin{array}{l}\text { Estrutura Conceitual para Elaboração e Divulgação } \\
\text { de Informação Contábil de Propósito Geral pelas En- } \\
\text { tidades do Setor Público }\end{array}$ & $\begin{array}{l}\text { Conceptual } \\
\text { Framework }\end{array}$ \\
\hline NBC TSP 01 & DOU 28/10/16 & Receita de Transação sem Contraprestação & IPSAS 23 \\
\hline NBC TSP 02 & DOU 28/10/16 & Receita de Transação com Contraprestação & IPSAS 9 \\
\hline NBC TSP 03 & DOU 28/10/16 & $\begin{array}{l}\text { Provisões, Passivos Contingentes e Ativos Contin- } \\
\text { gentes }\end{array}$ & IPSAS 19 \\
\hline NBC TSP 04 & DOU 06/12/16 & Estoques & IPSAS 12 \\
\hline NBC TSP 05 & DOU 06/12/16 & $\begin{array}{l}\text { Contratos de Concessão de Serviços Públicos: Conce- } \\
\text { dente }\end{array}$ & IPSAS 32 \\
\hline NBC TSP 06 & DOU 28/9/17 & Propriedade para Investimento & IPSAS 16 \\
\hline NBC TSP 07 & DOU 28/9/17 & Ativo Imobilizado & IPSAS 17 \\
\hline NBC TSP 08 & DOU 28/9/17 & Ativo Intangivel & IPSAS 31 \\
\hline NBC TSP 09 & DOU 28/9/17 & $\begin{array}{l}\text { Redução ao Valor Recuperável de Ativo Não Gerador } \\
\text { de Caixa }\end{array}$ & IPSAS 21 \\
\hline NBC TSP 10 & DOU 28/9/17 & $\begin{array}{l}\text { Redução ao Valor Recuperável de Ativo Gerador de } \\
\text { Caixa }\end{array}$ & IPSAS 26 \\
\hline NBC TSP 11 & DOU 31/10/18 & Apresentação das Demonstrações Contábeis & IPSAS 1 \\
\hline NBC TSP 12 & DOU 31/10/18 & Demonstração dos Fluxos de Caixa & IPSAS 2 \\
\hline
\end{tabular}

42 FEIJÓ, Paulo Henrique. Entendendo as mudanças na contabilidade aplicada ao Setor Público. Brasília: Editora Gestão Pública, 2013, p. 73 e ss. 


\begin{tabular}{|l|l|l|c|}
\hline NBC TSP 13 & DOU 31/10/18 & $\begin{array}{l}\text { Apresentação de Informação Orçamentária nas De- } \\
\text { monstrações Contábeis }\end{array}$ & IPSAS 24 \\
\hline NBC TSP 14 & DOU 31/10/18 & Custos de Empréstimos & IPSAS 5 \\
\hline NBC TSP 15 & DOU 31/10/18 & Benefícios a Empregados & IPSAS 39 \\
\hline NBC TSP 16 & DOU 31/10/18 & Demonstrações Contábeis Separadas & IPSAS 34 \\
\hline NBC TSP 17 & DOU 31/10/18 & Demonstrações Contábeis Consolidadas 35 \\
\hline NBC TSP 18 & DOU 31/10/18 & $\begin{array}{l}\text { Investimento em Coligada e em Empreendimento } \\
\text { Controlado em Conjunto }\end{array}$ & IPSAS 36 \\
\hline NBC TSP 19 & DOU 31/10/18 & Acordos em Conjunto & IPSAS 37 \\
\hline NBC TSP 20 & DOU 31/10/18 & Divulgação de Participações em Outras Entidades & IPSAS 38 \\
\hline NBC TSP 21 & DOU 31/10/18 & Combinações No Setor Público & IPSAS 40 \\
\hline NBC T 16.7 & $1.366 / 111$ & $\begin{array}{l}\text { Consolidação das Demonstrações Contábeis (revo- } \\
\text { gada a partir de 1\%/1/21) }\end{array}$ & não há \\
\hline NBC T 16.11 & Sistema de Informação de Custos do Setor Público & não há \\
\hline
\end{tabular}

Fonte: CFC, 2017. Disponível em <http://cfc.org.br/tecnica/normas-brasileiras-de-contabilidade/ nbc-tsp-do-setor-publico/> (acesso em 1\%/4/2019).

Vale frisar, no entanto, que as normas técnicas editadas pelo CFC não possuem vigência imediata na Administração Pública, isto é, não constituem normas jurídicas de observância obrigatória. No caso brasileiro, é o Manual de Contabilidade Aplicada ao Setor Público (MCASP), editado desde 2008 pela Secretaria do Tesouro Nacional (STN), que tem cumprido o papel de incorporar as normas técnicas ao arcabouço normativo infralegal pátrio ${ }^{43}$.

Em linhas gerais, a STN extrai seu mandato regulamentar do art. $50, \mathbb{2} 2^{\circ}$, da Lei de Responsabilidade Fiscal (LRF), segundo o qual "a edição de normas gerais para consolidação das contas públicas caberá ao órgão central de contabilidade da União, enquanto não implantado o conselho de que trata o art. 67 [o Conselho de Gestão Fiscal]". Também há referências aos artigos 111 e 113 da Lei n. 4.320/1964 ${ }^{44}$, que estabelecem competências que caberiam ao extinto Conse-

${ }^{43}$ Cf. FEIJÓ, Paulo Henrique. Entendendo as Mudanças na Contabilidade Aplicada ao Setor Público. Op. cit., p. 63 e 73.

${ }^{44}$ Transcrevo a seguir o art. 111, caput e art. 113, caput e parágrafo único, da Lei n. 4.320/1964: "Art. 111. O Conselho Técnico de Economia e Finanças do Ministério da Fazenda, além de outras apurações, para fins estatísticos, de interêsse nacional, organizará e publicará o balanço 
lho Técnico de Economia e Finanças do Ministério da Fazenda, suposto predecessor da STN para efeito de regulação contábil ${ }^{45}$.

De resto, a STN atua com base em atos infralegais, como a Portaria n. 184/2008 do Ministério da Fazenda ${ }^{46}$ e o Decreto n. 6.976/200947. Recentemente, o papel da STN como órgão regulador da contabilidade pública brasileira teve sua legitimidade reforçada com o advento da Lei Complementar n. 156/2016, que alterou a LRF para prever, entre outros pontos, que todos os entes federativos disponibilizarão suas informações e dados contábeis, orçamentários e fiscais conforme periodicidade, formato e sistema estabelecidos pelo órgão central de contabilidade da União $\left(\mathbb{S} 2^{\circ}\right.$ do art. $\left.48^{48}\right)$.

\section{DÍVIDA PÚBLICA E CONVERGÊNCIA AOS PADRÕES IPSAS: APORTES CRÍTICOS}

Apesar da retórica em prol da adoção dos padrões IPSAS por parte dos Estados nacionais, o fato é que esse processo não é isento de efeitos colaterais, alguns graves o bastante para que ponderemos se, de fato, a implantação desses padrões internacionais atende ao melhor interesse do Brasil (ou seja, o interesse

consolidado das contas da União, Estados, Municípios e Distrito Federal, suas autarquias e outras entidades, bem como um quadro estruturalmente idêntico, baseado em dados orçamentários.";

"Art. 113. Para fiel e uniforme aplicação das presentes normas, o Conselho Técnico de Economia e Finanças do Ministério da Fazenda atenderá a consultas, coligirá elementos, promoverá o intercâmbio de dados informativos, expedirá recomendações técnicas, quando solicitadas, e atualizará sempre que julgar conveniente, os anexos que integram a presente lei. Parágrafo único. Para os fins previstos neste artigo, poderão ser promovidas, quando necessário, conferências ou reuniões técnicas, com a participação de representantes das entidades abrangidas por estas normas.”

${ }^{45}$ Nessa linha, cf. FEIJÓ, Paulo Henrique. Entendendo as Mudanças na Contabilidade Aplicada ao Setor Público. Op. cit., p. 71.

46 A Portaria MF n. 184/2008 é expressa ao determinar que a STN promova a convergência das normas contábeis nacionais aos padrões IPSAS e às normas editadas pelo CFC.

47 Confira-se o teor do art. $4^{\circ}$ do Decreto n. 6.976/2009: “Art. 4. O Sistema de Contabilidade Federal tem como objetivo promover: I - a padronização e a consolidação das contas nacionais; II - a busca da convergência aos padrões internacionais de contabilidade, respeitados os aspectos formais e conceituais estabelecidos na legislação vigente; e III - o acompanhamento contínuo das normas contábeis aplicadas ao setor público, de modo a garantir que os princípios fundamentais de contabilidade sejam respeitados no âmbito do setor público."

48 Veja-se o inteiro teor do novo art. $48, \mathbb{S} 2^{\circ}$, da LRF, incluído pela Lei Complementar $n$. 156/2016: “Art. 48, $\mathbb{2} 2^{\circ}$ A União, os Estados, o Distrito Federal e os Municípios disponibilizarão suas informações e dados contábeis, orçamentários e fiscais conforme periodicidade, formato e sistema estabelecidos pelo órgão central de contabilidade da União, os quais deverão ser divulgados em meio eletrônico de amplo acesso público.” 
público). Esta seção, portanto, tem por escopo elucidar quais seriam os principais problemas associados ao processo de convergência aos padrões IPSAS, com destaque para aqueles que dizem respeito à mensuração do déficit público e do estoque da dívida. Começarei pelos pontos críticos apontados pela literatura estrangeira mais autorizada e na seção 6, concluirei este trabalho com uma breve análise do caso brasileiro.

\subsection{Literatura estrangeira}

A literatura estrangeira é repleta de observações críticas quanto à adoção do regime de competência ou dos padrões IPSAS. A Alemanha, por exemplo, é paradigma de nação desenvolvida hostil à implementação do regime de competência, destacando-se o receio de que a reforma poderia dificultar o controle parlamentar das finanças públicas ${ }^{49}$.

BELLANCA e VANDERNOOT, ao tratarem do caso belga, apontam que as IPSAS sofrem resistências internas, tendo em vista fatores como o alto custo para sua implantação, a incompletude dos padrões internacionais para o adequado tratamento contábil de pensões e benefícios sociais, além da complexidade e do caráter abstrato das IPSAS quando comparadas às regras da contabilidade orçamentária de caixa, de compreensão mais simples por parte de servidores e políticos ${ }^{50}$.

Já no contexto específico da França, CALMEL enfatiza que as características específicas do setor público, largamente informadas pelo conceito de soberania estatal, impedem que os padrões IPSAS e assemelhados sejam implementados em sua integralidade. Desse modo, segundo a autora, "os princípios de mensuração das obrigações financeiras na França excluem quaisquer referências ao valor de mercado atual, porque não é o papel de Central Governo intervir ativamente no mercado em uma base especulativa" ${ }^{51}$.

Em estudo comparado envolvendo Estados Unidos, Alemanha, França e Reino Unido, apontou-se um frequente descompasso entre a adoção da contabilidade $e x$ post com base no regime de competência e o funcionamento dos sistemas de orça-

49 JONES, Rowan; LÜDER, Klaus. The Federal Government of Germany's circumspection concerning accrual budgeting and accounting. Public Money \& Management, v. 31, n. 4, p. 265 $270,2011$.

50 BELLANCA, Sabrina; VANDERNOOT, Julien. Analysis of Belgian public accounting and its compliance with International Public Sector Accounting Standards (IPSAS) 1, 6 and 22. International Journal of Business and Management, v. 8, n. 9, p. 122, 2013.

51 CALMEL, Marie-Pierre. Harmonisation of EPSASs (European Public Sector Accounting Standards): Developments and Prospects. Accounting, Economics and Law, v. 4, n. 3, p. 215-236, 2014. 
mento público e estatísticas fiscais, que seriam os verdadeiros protagonistas do controle e do planejamento das finanças públicas em níveis micro e macroeconômico ${ }^{52}$.

Em relação às críticas, importante é destacar que, ao contrário os fomentadores do projeto IPSAS querem fazer crer, a adoção de padrões contábeis privatistas não representa apenas uma escolha técnica e neutra. Na verdade, como diz BIONDI, as regras contábeis “decidem que política é admissível e envolvem uma representação e um julgamento implícito de cada política que possa ser realizada dentro seu quadro". Assim, continua o autor, “a representação contábil dirige a própria definição de sustentabilidade da dívida pública, definindo o que é aceitável e permissível entre a administração pública e seus jurisdicionados (inclusive seus credores)" 53 .

O exemplo da Nova Zelândia é paradigmático. Segundo NEWBERRY, a reforma contábil implementada por aquele país trouxe consigo efeitos colaterais relevantes. Segundo a estudiosa, a adoção dos padrões IFRS (posteriormente IPSAS) acarretou uma significativa delegação de poderes a tecnocratas instalados no Tesouro, contribuindo para um enfraquecimento ainda maior do controle parlamentar, que viu o papel do orçamento público ser reduzido em comparação com o da contabilidade patrimonial ${ }^{54}$.

Ainda de acordo com NEWBERRY, a adoção de padrões contábeis privados veio também acompanhada de uma atuação mais agressiva do Executivo no mercado de capitais, culminando em um cenário de intensa alavancagem de ativos públicos por meio da reaplicação dos recursos no próprio mercado de capitais. Além da volatilidade que tal estratégia pode gerar, a autora ressalta que a alavancagem das receitas contribui para oferecer uma representação enganosa da saúde financeira do país, tendo por base o conceito de dívida pública líquida. Como se não bastasse, os analistas do mercado de capitais tornaram-se os usuários mais relevantes das informações financeiras governamentais, fazendo com que a linguagem dos demonstrativos contábeis ficasse cada vez menos acessível ao povo e a seus representantes parlamentares ${ }^{55}$.

Outro problema ínsito à reforma neozelandesa, ainda segundo NEWBERRY, seria a grande margem de discricionariedade atribuída aos geradores da informação contábil, que teriam certa liberdade para introduzir vieses (biases) nas infor-

\footnotetext{
52 JONES, Rowan et al. A comparison of budgeting and accounting reforms in the national governments of France, Germany, the UK and the US. Op. cit, passim.

53 BIONDI, Yuri. Harmonising European public sector accounting standards (EPSAS): issues and perspectives for Europe's economy and society. Op. cit., p. 173 (tradução livre).

${ }^{54}$ NEWBERRY, Susan. The use of accrual accounting in New Zealand's central government: Second thoughts. Op. cit., p. 285/287.

${ }_{55}$ Idem, ibidem, p. 288/289 e 292.
} 
mações contábeis. A distinção entre passivos contingentes e passivos efetivos, por exemplo, ofereceria uma válvula de escape para o fomento de políticas de austeridade em tempos de crise. Nas palavras de NEWBERRY, "durante a crise financeira global, os governos internacionalmente aceitaram e impuseram a seus cidadãos e contribuintes passivos que não eram aparentes antes da crise à medida que tentavam conter a crise com ajudas a bancos e outras instituições financeiras." ${ }^{56}$

\section{DISCUSSÃO E CONCLUSÃO: O CASO BRASILEIRO}

Quanto ao Brasil, ainda são incertos os efeitos da convergência dos IPSAS sobre a gestão das finanças públicas (e, mais especificamente, sobre a gestão da dívida pública).

Dívida pública, como se sabe, é um conceito fluido, sujeito a diferentes métricas e prismas de análise ${ }^{57}$. Em outras palavras: o conceito, o tamanho e aceitabilidade da dívida pública dependem largamente dos critérios disponíveis e empregados para conceituá-la, medi-la e julgá-la, conforme o alerta de BIONDI ${ }^{58}$. Nesse contexto, tendo a acreditar que o impacto das normas contábeis convergidas sobre a gestão da dívida pública será diretamente proporcional à importância que tais normas venham a adquirir no cenário institucional brasileiro.

Por um lado, o fato é que a dívida pública brasileira e conceitos aparentados (e.g. operações de crédito) devem estar representados nos diferentes espaços contábeis, a saber, o espaço orçamentário, o espaço patrimonial e o espaço fiscal. É notório, por exemplo, que todas as receitas e despesas relativas à dívida devem constar do orçamento público (art. $5^{\circ}, \mathbb{} 1^{\circ}$, da LRF) e que os recursos oriundos de operações de crédito são apurados no orçamento como receitas de capital (art. 11 da Lei n. 4.320/1964). A contabilidade patrimonial, por seu turno, emprega noções ínsitas à dívida pública, como ativos, passivos, receitas e despesas. Aliás, como já foi dito, há um campo considerável de sobreposição entre contabilidade patrimonial e estatísticas fiscais, conforme apontado pela Estrutura Conceitual das IPSAS.

Contudo, é no campo das estatísticas fiscais que se dá verdadeiramente a gestão da dívida pública, tendo em vista o seu viés macroeconômico. A contabilidade patrimonial e os dados da execução orçamentária e financeira ingressam

${ }^{56}$ Idem, ibidem, p. 294.

57 Sobre o tema, v. CONTI, José Mauricio. Devo, não nego: o Direito Financeiro e o dilema da divida pública. Conjur (on line), 17/10/2017. Disponível em < https://www.conjur.com.br/2017-out-17/contas-vista-devo-nao-nego-direito-financeiro-dilema-divida-publica\#_ftn3> (acesso em 07/11/17).

58 BIONDI, Yuri. Harmonising European public sector accounting standards (EPSAS): issues and perspectives for Europe's economy and society. Op. cit., p. 172/173. 
teoricamente como fontes de dados, municiando os órgãos elaboradores das estatísticas. A questão, portanto, é saber em que medida os dados da contabilidade patrimonial passariam a alimentar efetivamente as estatísticas fiscais do Brasil.

Atualmente, ao contrário do que se poderia supor, é a autoridade monetária que protagoniza a medição da dívida pública. No cenário de hoje, a contabilidade pública é ignorada pelo Banco Central (Bacen), que produz suas estatísticas com base em dados do setor bancário ${ }^{59}$. E isso parece decorrer de fatores históricos, já que a contabilidade pública não se mostrava confiável quando as estatísticas fiscais começaram a ser produzidas ${ }^{60}$. Posteriormente, o Tribunal de Contas da União referendaria parcialmente a metodologia empregada pelo Bacen para o cálculo das Necessidades de Financiamento do Setor Público (NFSP) e da Dívida Líquida do Setor Público (DLSP ${ }^{61}$. Desse modo, parece improvável que os padrões IPSAS venham a causar impacto direto nas estatísticas fiscais do Bacen a curto prazo.

Caso venham uma dia a influenciar diretamente a gestão macroeconômica $\mathrm{da}$ dívida, as normas convergidas às IPSAS podem gerar alguns problemas. Veja-se, por exemplo, a diretriz de que o regime da competência deva ser aplicado indistintamente a receitas e despesas, em detrimento do disposto no art. 35 da Lei n. 4.320/1964. Esse entendimento já foi chancelado pelo Tribunal de Contas da União por meio do Acórdão n. 158/2012, Plenário, Rel. Raimundo Carreiro. Nesse julgado, entendeu a Corte de Contas que o art. 35 da Lei n. 4.320/1964 estaria restrito ao campo orçamentário, não sendo vedado à STN promover o registro das variações patrimoniais positivas e negativas com base exclusivamente no regime de competência. Ora, se levada em conta no cálculo da dívida pública, a apuração da receita conforme o regime de competência geraria redução da dívida líquida antes da efetiva arrecadação dos recursos, ocasionando expansão fiscal artificiosa e quebra do princípio contábil da prudência, conforme alertado pela Secretaria de Macroavaliação Governamental do próprio TCU. O exemplo evidencia que a análise do tema inspira cautela.

De resto, é possível afirmar com alguma segurança que a convergência aos padrões IPSAS não destoa dos ditames da Constituição dirigente invertida, na linha do trabalho de BERCOVICI e MASSONETTO. O fato é que o modelo IPSAS pa-

59 Em sentido crítico, cf. AFONSO, José Roberto. Dívida Pública no Brasil: medidas e significados. Espaço Jurídico Journal of Law [EJJL], n. 2, p. 309-320, 2017.

${ }^{60}$ Nessa linha, cf. CARVAlHO JR., Antonio Carlos Costa D’Ávila e FEIJÓ, Paulo Henrique. Entendendo Resultados Fiscais: Teoria e Prática de Resultados Primário e Nominal. Brasília: Editora Gestão Pública, 2015, p. 123/124.

${ }^{61}$ Cf. os seguintes julgados do TCU: Acórdão n. 0324/2006 - Primeira Câmara, Acórdão 3424/2007 - $1^{\text {a }}$ Câmara, Acórdão n. 3.427/2007 e Acórdão 7469/2012 - Primeira Câmara, Acórdão 7.469/2012 - Primeira Câmara e Acórdão n. 1.776/2012-Plenário. 
rece obedecer claramente à dinâmica liberalizante da governança global, que intenciona diminuir custos de transação por meio da eliminação de peculiaridades nacionais, facilitando o monitoramento e a análise da posição financeira dos Estados devedores. Nesse contexto, as normas contábeis passam a priorizar o usuário externo em detrimento dos órgãos de controle democráticos. Por fim, deve-se apontar também que uma conceituação maximalista do conceito de passivos em detrimento de uma noção mais larga de passivos contingentes poderia servir de estímulo a políticas desmedidas de austeridade fiscal, conforme apontado por NEWBERRY.

\section{REFERÊNCIAS}

ADHIKARI, Pawan; KURUPPU, Chamara; MATILAL, Sumohon. Dissemination and institutionalization of public sector accounting reforms in less developed countries: A comparative study of the Nepalese and Sri Lankan central governments. In: Accounting Forum. Elsevier, 2013. p. 213-230.

AFONSO, José Roberto. Dívida Pública no Brasil: medidas e significados. Espaço Jurídico Journal of Law [EJJL], n. 2, p. 309-320, 2017.

ANDRADE, Maria Elisabeth Moreira Carvalho; CARVALHO, Luiz Nelson Guedes de. Análise da adoção do regime de competência no setor público internacional. Revista FSA (Faculdade Santo Agostinho), v. 10, n. 1, 2013, p. 42.

ANESSI-PESSINA, E. and STECCOLINI, I. Effects of Budgetary and Accruals Accounting Coexistence: Evidence from Italian Local Governments. Financial Accountability \& Management, Vol. 23, No. 2, 2007.

BELLANCA, Sabrina; VANDERNOOT, Julien. Analysis of Belgian public accounting and its compliance with International Public Sector Accounting Standards (IPSAS) 1, 6 and 22. International Journal of Business and Management, v. 8, n. 9, p. 122, 2013.

BERCOVICI, Gilberto e MASSONETTO, Luís Fernando. A Constituição Dirigente Invertida: a blindagem da constituição financeira e a agonia da constituição econômica. Boletim de Ciências Económicas, v. XLIX, p. 57-77, 2006.

BERCOVICI, Gilberto. A problemática da constituição dirigente: algumas considerações sobre o caso brasileiro. Revista de Informação Legislativa, v. 4, n. 15, 1999.

BIONDI, Yuri. Harmonising European public sector accounting standards (EPSAS): issues and perspectives for Europe's economy and society. Accounting, Economics and Law, v. 4, n. 3, p. 165-178, 2014.

BORGES, Thiago Bernardo et al. Desmistificação do regime contábil de competência. Revista de Administração Pública-RAP, v. 44, n. 4, 2010.

BOTZEM, Sebastian. The Politics of Accounting Regulation: Organizing Transnational Standard-Setting in Financial Reporting. Cheltenham: Edward Elgar, 2014.

BRESSER-PEREIRA, Luiz Carlos. A reforma gerencial do Estado de 1995. Revista de administração pública, v. 34, n. 4, p. 7-26, 2000. 
BRUSCA, Isabel; GÓMEZ-VILLEGAS, Mauricio; MONTESINOS, Vicente. Public Financial Management Reforms: The Role of Ipsas in Latin-America. Public Administration and Development, v. 36, n. 1, p. 51-64, 2016.

BRUSCA, Isabel; MONTESINOS, Vicente; CHOW, Danny SL. Legitimating international public sector accounting standards (IPSAS): the case of Spain. Public Money \& Management, v. 33, n. 6, p. 437-444, 2013.

CALMEL, Marie-Pierre. Harmonisation of EPSASs (European Public Sector Accounting Standards): Developments and Prospects. Accounting, Economics and Law, v. 4, n. 3, p. 215-236, 2014.

CANOTILHO, José Joaquim Gomes. Direito Constitucional e Teoria da Constituição. Coimbra: Almedina, $6^{\text {a }}$ ed, 2002.

CARVAlHO JR., Antonio Carlos Costa D’Ávila e FEIJÓ, Paulo Henrique.

Entendendo Resultados Fiscais: Teoria e Prática de Resultados Primário e Nominal. Brasília: Editora Gestão Pública, 2015, p. 123/124.

CARVALHO, José Augusto Moreira de. Arts. 34 a 39. In: CONTI, José Mauricio (coord.).Orçamentos Públicos: a Lei 4.320/1964 Comentada. São Paulo: Ed. Revista dos Tribunais, 2014.

COMISSÃO EUROPEIA. Relatório da Comissão ao Conselho e ao Parlamento relativo à aplicação de normas de contabilidade harmonizadas do setor público nos Estados-Membros. COM (2013) 114, 2013. Disponível em: <http://eur-lex.europa.eu/ legal-content/EN/TXT/?qid=1410447825715\&uri=CELEX:52013DC0114> (acesso em 07/12/17).

CONSELHO EUROPEU. Diretiva 2011/85/EU do Conselho. Disponível em: <http:// eur-lex.europa.eu/legal-content/EN/TXT/?uri=uriserv:OJ.L_.2011.306.01.0041.01. ENG> (acesso em 07/12/17).

CONSELHO FEDERAL DE CONTABILIDADE. NBC TSP - Estrutura Conceitual. Prefácio. Brasília, 2016. O documento encontra-se disponível em <http://www2.cfc.org. br/sisweb/sre/detalhes_sre.aspx?Codigo=2016/NBCTSPEC\&arquivo=NBCTSPEC.doc $>$ (acesso em 07/12/17).

CONTI, José Mauricio. Devo, não nego: o Direito Financeiro e o dilema da dívida pública. Conjur (on line), 17/10/2017. Disponível em < https://www.conjur.com. br/2017-out-17/contas-vista-devo-nao-nego-direito-financeiro-dilema-divida-publica\#_ ftn3> (acesso em 07/11/17).

FEIJÓ, Paulo Henrique. Entendendo as Mudanças na Contabilidade Aplicada ao Setor Público. Brasília: Editora Gestão Pública, 2013.

FEIJÓ, Paulo Henrique; CARVALHO JÚNIOR, Jorge Pinto de; RIBEIRO, Carlos Eduardo. Entendendo a Contabilidade Orçamentária Aplicada ao Setor Público. Brasília: Editora Gestão Pública, 2015.

HOPPER, Trevor; LASSOU, Philippe; SOOBAROYEN, Teerooven. Globalisation, accounting and developing countries. Critical Perspectives on Accounting, v. 43, p. 125-148, 2017. 
INTERNATIONAL FEDERATION OF ACCOUNTANTS - IFAC. IPSASB Strategy Consultation, 2014, p. 10/11. Disponível em <http://www.ifac.org/system/files/ publications/files/IPSASB-Strategy-Consultation-2015-2019_0.pdf> (acesso em 08/12/2017).

\section{INTERNATIONAL FEDERATION OF ACCOUNTANTS. Handbook of}

International Public Sector Accounting Pronouncements, v. 1, jan., 2016, p. 828-853. Disponível em < http://www.ifac.org/publications-resources/2016-handbookinternational-public-sector-accounting-pronouncements> (acesso em 07/12/2017).

JONES, Rowan et al. A comparison of budgeting and accounting reforms in the national governments of France, Germany, the UK and the US. Financial Accountability \& Management, v. 29, n. 4, p. 419-441, 2013.

JONES, Rowan; CARUANA, Josette. A perspective on the proposal for European public sector accounting standards, in the context of accruals in UK government accounting. Accounting, Economics and Law, v. 4, n. 3, p. 265-282, 2014.

JONES, Rowan; LÜDER, Klaus. The Federal Government of Germany's circumspection concerning accrual budgeting and accounting. Public Money \& Management, v. 31, n. 4, p. 265-270, 2011.

MAGALHÃES, Fábio Rodrigues et al. NBCASP e IPSAS: uma análise do processo de convergência brasileira sob a ótica do accrual basis accounting. Revista Brasileira de Contabilidade, n. 201, p. 56-67, 2013.

MAPURUNGA, Patrícia Vasconcelos Rocha; DE MENESES, Anelise Florencio; PETER, Maria da Glória Arrais. O processo de convergência das normas internacionais de contabilidade: uma realidade nos setores privado e público brasileiros. Revista Controle-doutrinas e artigos, v. 9, n. 1, p. 87-107, 2011.

MATIAS-PEREIRA, José. Administração pública comparada: uma avaliação das reformas administrativas do Brasil, EUA e União Europeia. Revista de Administração Pública, v. 42, n. 01, p. 61/82, 2008.

NEU, Dean; OCAMPO, Elizabeth. Doing missionary work: The World Bank and the diffusion of financial practices. Critical Perspectives on Accounting, v. 18, n. 3, p. 363-389, 2007.

NEWBERRY, Susan. The use of accrual accounting in New Zealand's central government: Second thoughts. Accounting, Economics and Law, v. 4, n. 3, p. 283-297, 2014.

NINO, Carlos Santiago. Introdução à Análise do Direito. Trad. Elza Maria Gasparotto. São Paulo: Martins Fontes, 2010.

SARMENTO, Daniel e SOUZA NETO, Cláudio Pereira de. Direito Constitucional Teoria, História e Métodos de Trabalho. Belo Horizonte: Fórum, 2012. 